\title{
The impact of body mass index on inpatient- versus outpatient-treated chronic obstructive pulmonary disease exacerbations
}

\author{
Ariane Jacob PhD(c) ${ }^{1,2,3}$, Catherine Laurin $\mathrm{PhD}^{1,2,4}$, Kim L Lavoie $\mathrm{PhD}^{1,2,3,5}$, Gregory Moullec $\mathrm{PhD}^{1,2,4}$, \\ Maxine Boudreau $\mathrm{PhD}(\mathrm{c})^{1,2,3}$, Catherine Lemière $M D^{2}$, Simon L Bacon $\mathrm{PhD}^{1,2,4,5}$
}

\begin{abstract}
A Jacob, C Laurin, KL Lavoie, et al. The impact of body mass index on inpatient- versus outpatient-treated chronic obstructive pulmonary disease exacerbations. Can Respir J 2013;20(4):237-242.
\end{abstract}

BACKGROUND: Increased body weight has been associated with worse prognoses for many chronic diseases; however, this relationship is less clear in patients with chronic obstructive pulmonary disease (COPD), with underweight patients experiencing higher morbidity than normal or overweight patients.

OBJECTIVE: To assess the impact of body mass index (BMI) on the risk for COPD exacerbations.

METHODS: The present study included 115 patients with stable COPD (53\% women; mean $[ \pm \mathrm{SD}]$ age $67 \pm 8$ years). Height and weight were measured to calculate BMI. Patients were followed for a mean of $1.8 \pm 0.8$ years to assess the prospective risk of inpatient-treated exacerbations and outpatienttreated exacerbations, all of which were verified by chart review.

RESULTS: Cox regression models revealed that underweight patients were at greater risk for inhospital-treated exacerbations (RR 2.93 [95\% CI 1.27 to 6.76) relative to normal weight patients. However, overweight (RR 0.59 [95\% CI 0.33 to 1.57 ) and obese (RR 0.99 [95\% CI 0.53 to 1.86$]$ ) patients did not differ from normal weight patients. All analyses were adjusted for age, sex, length of diagnosis, smoking pack-years, forced expiratory volume in $1 \mathrm{~s}$, and time between recruitment and last exacerbation. BMI did not influence the risk of out-of-hospital exacerbations.

CONCLUSIONS: The present study showed that underweight patients were at greater risk for inhospital exacerbations. However, BMI did not appear to be a risk factor for out-of-hospital exacerbations. This suggests that the BMI-exacerbation link may differ according to the nature of the exacerbation, the mechanisms for which are not yet known.

Key Words: Body mass index; Chronic obstructive pulmonary disease; Cohort studies; Disease progression; Exacerbations; Pulmonary disease

C hronic obstructive pulmonary disease (COPD) is the third leading cause of death in North America (1) and affects 210 million adults worldwide (2). The course of the disease is characterized by recurrent exacerbations (ie, significant symptom deterioration requiring additional therapy) (3), which are associated with decreased lung function (4), increased rates of hospitalization (4), deterioration in quality of life (4-6), increased health care costs (7) and premature mortality (5).

Several risk factors for exacerbations have been identified (eg, cigarette smoking, decreased lung function [ie, forced expiratory volume in $\left.1 \mathrm{~s}\left(\mathrm{FEV}_{1}\right)\right]$ ), previous exacerbations $(8)$ and a low body mass index (BMI) $(5,9)$. Low BMI has been shown to be an important risk factor for inhospital-treated exacerbations in several studies. For example, two prospective studies showed that having a low BMI $\left(<18.5 \mathrm{~kg} / \mathrm{m}^{2}\right)$ was a risk factor for COPD-related hospitalizations among stable COPD patients $(7,9)$. One major limitation of studies to date linking low BMI to exacerbation risk is that they have only
Les conséquences de l'indice de masse corporelle sur les exacerbations de maladie pulmonaire obstructive chronique chez les patients hospitalisés ou soignés en consultations externes

HISTORIQUE : Un poids élevé s'associe à un pronostic plus sombre à l'égard de nombreuses maladies chroniques, mais ce lien est moins évident chez les patients atteints d'une maladie pulmonaire obstructive chronique (MPOC), car les patients en insuffisance pondérale présentent une morbidité plus élevée que ceux en surcharge pondérale ou au poids normal.

OBJECTIF : Évaluer les répercussions de l'indice de masse corporelle (IMC) sur le risque d'exacerbations de MPOC.

MÉTHODOLOGIE : La présente étude portait sur 115 patients ayant une MPOC stable ( $53 \%$ de femmes; âge moyen [ $[ \pm E ́ T]$ de $67 \pm 8$ ans). Les chercheurs ont mesuré leur taille et leur poids pour calculer leur IMC. Ils ont suivi les patients pendant une moyenne de $1,8 \pm 0,8$ an pour évaluer le risque prospectif d'exacerbations des patients hospitalisés et des patients soignés en consultations externes et ont vérifié le tout par une analyse des dossiers.

RÉSULTATS : Les modèles de régression de Cox ont révélé que les patients en insuffisance pondérale étaient plus vulnérables aux exacerbations en cas d'hospitalisation (RRR 2,93 [95 \% IC 1,27 à 6,76]) que les patients de poids normal. Cependant, les patients faisant de l'embonpoint (RRR 0,59 [95 \% IC 0,33 à 1,57]) ou obèses (RRR 0,99 [95 \% IC 0,53 à 1,86]) n'obtenaient pas des résultats différents de ceux des patients de poids normal. Toutes les analyses étaient rajustées en fonction de l'âge, du sexe, du délai avant le diagnostic, du nombre de paquets de cigarettes par année, du volume expiratoire maximal par seconde et du délai entre le recrutement et la dernière exacerbation. L'IMC n'influait pas sur le risque d'exacerbations hors du milieu hospitalier.

CONCLUSIONS :La présente étude a révélé que les patients en insuffisance pondérale étaient plus vulnérables aux exacerbations en milieu hospitalier. Cependant, l'IMC ne semblait pas être un facteur de risque d'exacerbations hors du milieu hospitalier. Ainsi, le lien entre l'IMC et l'exacerbation pourrait différer selon la nature de l'exacerbation, dont on ne connaît pas encore les mécanismes.

focused on risk associated with exacerbations treated in hospital. In fact, with the rise of self-management programs, including written action plans that are implemented in consultation with a case manager, nurse or physician (10-12), outpatient exacerbations have grown to be at least two times more prevalent than inpatient-treated exacerbations (13). The goal of treating exacerbations on an outpatient basis is to intervene early (ie, at the onset of symptom deterioration) to reduce the escalation of an exacerbation that may have otherwise resulted in an emergency department visit or hospitalization (10). Although generally incurring lower costs than inpatient-treated exacerbations, outpatient-treated exacerbations remain associated with significant health care costs (eg, nurse time, medication costs) and have significant impacts on quality of life and health status $(6,14,15)$. The fact that the literature examining the link between BMI and COPD exacerbations has focused exclusively on inpatienttreated exacerbations has resulted in an incomplete picture of the true impact of BMI on exacerbation risk.

${ }^{1}$ Montreal Behavioural Medicine Centre, Hôpital du Sacré-Coeur de Montréal; ${ }^{2}$ Research Centre, Hôpital du Sacré-Coeur de Montréal;

${ }^{3}$ Department of Psychology, University of Quebec at Montreal (UQAM), Succursale Centre-Ville; ${ }^{4}$ Department of Exercise Science,

Concordia University; ${ }^{5}$ Research Centre, Montreal Heart Institute, Montreal, Quebec

Correspondence: Dr Simon L Bacon, Montreal Behavioural Medicine Centre, Hôpital du Sacré-Coeur de Montréal, J-3190, 5400 Gouin West,

Montréal, Québec H4J 1C5. Telephone 514-338-2222 ext 3709, fax 514-338-3123, e-mail simon.bacon@concordia.ca 
The aim of the present study was to prospectively assess the impact of BMI on the risk of inpatient- and outpatient-treated exacerbations in patients with COPD. We hypothesized that patients with a low BMI (ie, underweight) would be at greater risk for both inpatient- and outpatient-treated exacerbations relative to patients with normal BMI.

\section{METHODS}

\section{Patients}

The present study was a subanalysis of a previous study assessing the impact of psychiatric disorders on the risk for COPD exacerbations (13). Briefly, 115 stable COPD patients were recruited between April 2003 and December 2005 from the outpatient COPD clinics of two community hospitals in the Montreal (Quebec) area (Hôpital du SacréCoeur de Montréal and Hôpital de Saint-Eustache). To be included in the study, patients had to be $<85$ years of age, have received a clinical diagnosis of COPD (confirmed by spirometry), have been hospitalized for an exacerbation in the past 24 months but be stable at the time of the recruitment ( $\geq 4$ weeks without an exacerbation), and have a smoking history of at least 10 pack-years. Patients were excluded if they had a medical condition more severe than their COPD (eg, cancer, heart failure or a notable medical event in the past six months) or an apparent cognitive deficit (eg, dementia). The severity of a comorbid condition (ie, susceptible to generate medical events [eg, myocardial infarction, hospitalization] or death during the follow-up) was defined by a physician following chart review. The most conservative definition of this was used so that any suspicion of a more severe medical condition was considered to be an exclusion criterion. Patients were also excluded if they were living in a long-term health care centre. The human ethics committee of both study institutions approved the study and written informed consent was obtained from all participants.

\section{Protocol}

Baseline assessment: Patients meeting eligibility criteria were interviewed at one of the hospital sites by a trained clinical research assistant. All patients underwent a sociodemographic, medical/COPD history and psychiatric interview, and susequently completed a questionnaire battery. This battery included a dyspnea severity evaluation using the five-point Medical Research Council scale (16). All medical information was confirmed by chart review. Participants also underwent pulmonary function testing (ie, standard spirometry), yielding $\mathrm{FEV}_{1}$ and forced vital capacity (FVC) values. Finally, height and weight were measured by a research assistant to calculate BMI (weight divided by height in metres squared $\left[\mathrm{kg} / \mathrm{m}^{2}\right]$ ). Using standard international cut-off points, the following four groups of patients were defined: underweight (BMI $<18.5 \mathrm{~kg} / \mathrm{m}^{2}$ ); normal weight (BMI $18.5 \mathrm{~kg} / \mathrm{m}^{2}$ to $24.9 \mathrm{~kg} / \mathrm{m}^{2}$ ); overweight (BMI $25.0 \mathrm{~kg} / \mathrm{m}^{2}$ to $29.9 \mathrm{~kg} / \mathrm{m}^{2}$ ); and obese (BMI $\left.\geq 30.0 \mathrm{~kg} / \mathrm{m}^{2}\right)(17)$.

Follow-up assessment: Details regarding the follow-up procedure and exacerbations assessments (including quality control measures) have been reported previously (13). Briefly, an event-based definition of exacerbations was used, which is characterized by any symptom deterioration requiring a change in usual treatment. Instead of ascertaining exacerbations based on the clinical presentation (which includes several factors), a health care utilization definition (either requiring additional health care-prescribed corticosteroids or antibiotic treatment [outpatient] or requiring emergency department/hospital visit [inpatient]) of exacerbation was used. First, this way of measuring exacerbations can be considered to be more clinically relevant because it corresponds to those documented in the patient's medical chart (ie, events that directly engaged the health care system). Second, it also provides more consistent exacerbation start and end data. A number of exacerbations are known to not return to baseline, which significantly blurs the definition of what is a new exacerbation and what is a recurrence of a previous exacerbation. As previously defined (13), the following guidelines were used to differentiate exacerbations when overlap occurred: If a new set of medications were prescribed $24 \mathrm{~h}$ after the completion of those prescribed for the outpatient exacerbation, this was considered a second event, irrespective of the time between completion of the first and the second prescription; an exacerbation that started in an outpatient setting and resulted in subsequent inpatient visit before completing the medication in the outpatient setting was considered to be a single inpatient exacerbation; and if, after an inpatient exacerbation, a patient was prescribed ambulatory medication to be taken at home, it was not considered to be a separate event and constituted a single inpatient event. Exacerbation rates (dates, duration, and type of management) were assessed via monthly telephone interviews and medical chart review.

\section{Statistical analysis}

The weighted average number of exacerbations per person-year were calculated using standard procedures (13). Annual rates of exacerbations (any exacerbation, in- and outpatient treated) as a function of BMI group were analyzed using the GENMOD function in SAS (SAS Institute, USA) controlling for overdispersion, with normal-weight patients serving as the reference group (18). Cox proportional hazards regression was used to measure the relative risk (RR) and 95\% CIs of experiencing an exacerbation associated with BMI, with normalweight patients serving as the reference group. For these analyses, time was calculated as the interval between the initial baseline interview and the occurrence of the first event. Covariates were determined a priori (13) and included age, sex, duration of diagnosis, smoking pack-years, COPD severity (ie, $\mathrm{FEV}_{1}$ ), and time between recruitment and the patient's most recent previous exacerbation. In addition to the a priori covariates, a series of sensitivity analyses that were requested by the reviewers of the manuscript were also conducted. These extra analyses included leukotriene antagonist and $\mathrm{FEV}_{1} / \mathrm{FVC}$ ratio as additional covariates. All analyses were two-sided and $\mathrm{P}<0.05$ was considered to be statistically significant. All analyses were conducted using SAS version 9.2 (SAS Institute, USA).

\section{Patient baseline characteristics}

\section{RESULTS}

Patients were followed for a mean $( \pm \mathrm{SD})$ of $1.8 \pm 0.8$ years, ranging from 0.3 to 3.3 years. The mean age of the present cohort was $67 \pm 8$ years and included $54(49 \%)$ men. The mean \% predicted $\mathrm{FEV}_{1}$ was $42 \pm 17 \%$, which indicates that most patients could be classified as Global initiative for chronic obstructive Lung Diseases (GOLD) stage II or III (19). A total of $9 \%(n=10)$ of patients were underweight, $36 \%(n=41)$ were normal weight, $33 \%(n=38)$ were overweight and $22 \%(n=26)$ were obese. Sociodemographic and COPD characteristics presented as a function of BMI group are presented in Table 1. The four BMI groups significantly differed in terms of $\mathrm{FEV}_{1} / \mathrm{FVC}$ ratio, with underweight patients having poorer lung function than all of the other groups. Moreover, significantly more underweight patients were current smokers. In addition, there were significant differences in leukotriene antagonist use across the BMI categories with fewer underweight patients taking these medications. There were no other significant differences among the groups.

\section{Annual rate of exacerbations}

The weighted annual rates of exacerbations for the entire group were 3.3 for any exacerbation, 2.2 for outpatient-treated exacerbations, and 1.1 for exacerbations treated in hospital. Assessment of the raw distribution of the exacerbations across the four BMI groups found no discernible or apparent systematic difference across the four groups, meaning that any significant findings are less likely to be driven by skewed data. Weighted annual rates for each BMI group are reported in Table 2. Analyses revealed a significant main effect of BMI on inpatient-treated exacerbations, with overweight patients having a significantly reduced annual rate of exacerbations compared with the normal weight group, which was maintained after covariate adjustment. Analyses also revealed a significant main effect of BMI on any 


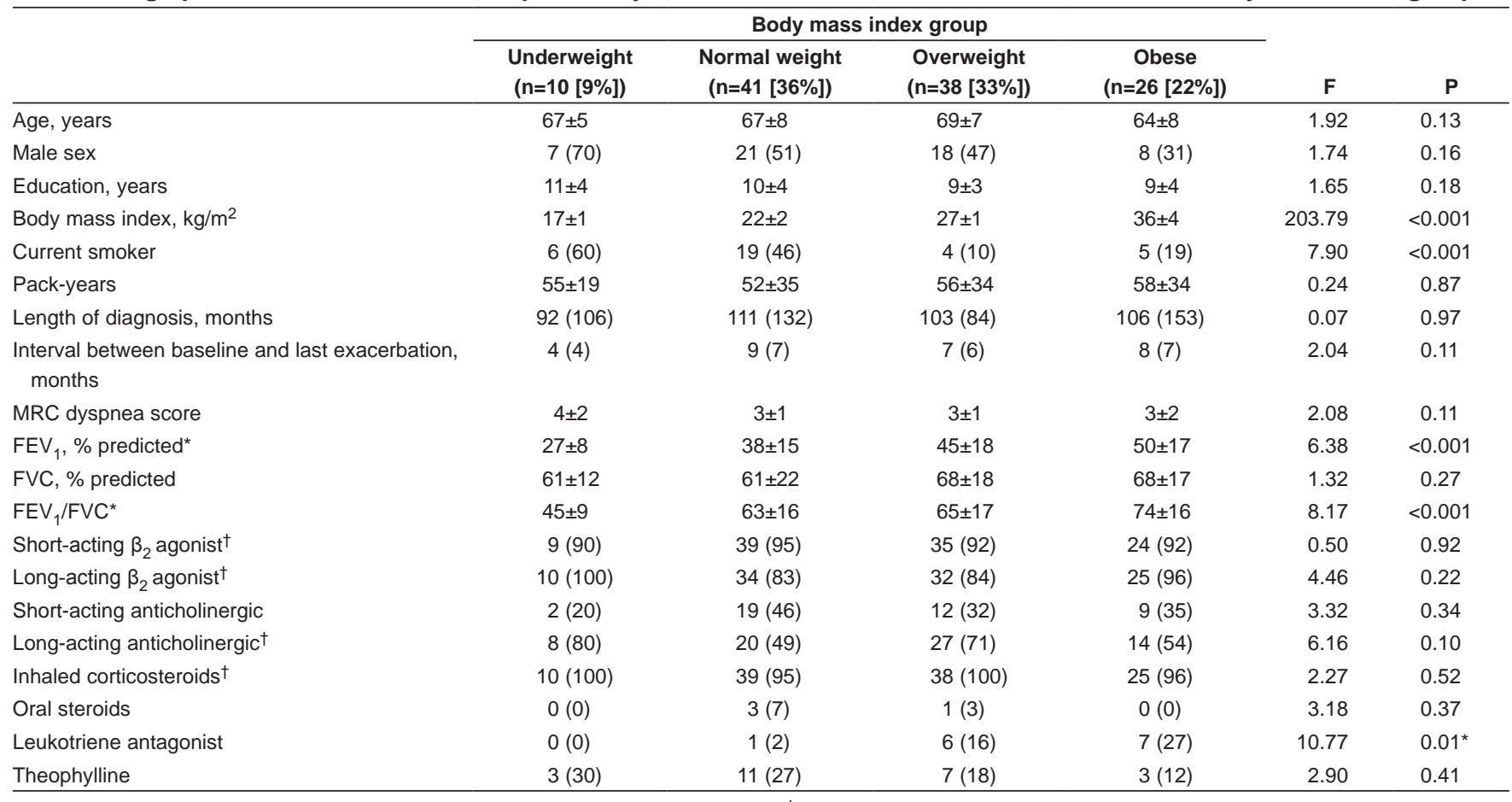

Data presented as mean $\pm S D$ or $n(\%) .{ }^{*}$ Significantly different from normal weight; ${ }^{\dagger}$ This medication could have been in a single inhaler or combined with another medication. FEV 1 Forced expiratory volume in 1 s; FVC Forced vital capacity; MRC Medical Research Council scale

exacerbation. Post hoc analyses revealed that this effect was driven by an increased rate of any exacerbation in underweight patients and a decreased rate in overweight patients, compared with normal weight patients. However, when adjusting for covariates, this main effect became a trend. Due to the relatively small sample size and number of covariates, additional analyses were performed collapsing the residual effects of the individual covariates into one covariate (thus reducing the degrees of freedom used). These analyses revealed a significant main effect of BMI on annual rates of any exacerbation $(F=3.62$; $\mathrm{P}=0.016)$. This suggests that the lack of significance in the covariateadjusted model was likely a model issue rather than a true lack of an effect of BMI on the rate of any exacerbation. There was no statistically significant increased rate of outpatient-treated exacerbations associated with any BMI group.

\section{BMI and exacerbations}

The RRs of experiencing a first exacerbation according to BMI are presented in Table 3. Results of the Cox regression analysis revealed that being underweight conferred an almost three times greater risk of experiencing a first inpatient-treated exacerbation compared with normal weight patients $(\mathrm{RR}=2.93)$. Moreover, there was a trend for individuals who were overweight to have a lower risk for inpatienttreated exacerbations compared with normal weight patients. Being obese was not associated with any increased risk of inpatient-treated exacerbations. No other significant effects of BMI on exacerbation risk (ie, any or outpatient treated) were observed.

As mentioned in the Methods section, a sensitivity analyses in which a leukotriene antagonist and $\mathrm{FEV}_{1} / \mathrm{FVC}$ ratio as additional covariates was included in response to requests from the reviewers of the manuscript. These analyses did not alter the main findings for the low BMI group and made the trend in the overweight group significant.

\section{DISCUSSION}

To our knowledge, the present prospective study was the first to investigate the impact of BMI on the risk for both in- and outpatienttreated exacerbations in patients with stable COPD. We hypothesized
TABLE 2

Annual rate of exacerbations as a function of body mass index group

\begin{tabular}{|c|c|c|c|c|c|c|}
\hline \multirow[b]{2}{*}{$\begin{array}{l}\text { Weighted } \\
\text { mean }\end{array}$} & \multicolumn{4}{|c|}{ Body mass index group } & \multirow[b]{2}{*}{$\mathbf{F}$} & \multirow[b]{2}{*}{$\mathbf{P}$} \\
\hline & $\begin{array}{l}\text { Underweight } \\
(n=10 \text { [9\%]) }\end{array}$ & $\begin{array}{c}\text { Normal } \\
\text { weight } \\
(n=41 \\
[36 \%])\end{array}$ & $\begin{array}{c}\text { Overweight } \\
(n=38 \\
[33 \%])\end{array}$ & $\begin{array}{l}\text { Obese } \\
(n=26 \\
[22 \%])\end{array}$ & & \\
\hline \multicolumn{7}{|c|}{ Outpatient-treated exacerbations } \\
\hline Unadjusted & 3.32 & 2.27 & 2.07 & 2.15 & 0.95 & 0.42 \\
\hline Adjusted & 3.54 & 2.23 & 2.18 & 2.74 & 1.03 & 0.38 \\
\hline \multicolumn{7}{|c|}{ Inhospital-treated exacerbations } \\
\hline Unadjusted & 2.23 & 1.39 & $0.76^{*}$ & 0.79 & 3.20 & 0.03 \\
\hline Adjusted & 2.07 & 1.46 & $0.67^{*}$ & 0.88 & 3.44 & 0.02 \\
\hline \multicolumn{7}{|c|}{ Any exacerbations } \\
\hline Unadjusted & $5.55^{\dagger}$ & 3.66 & $2.82^{\dagger}$ & 2.80 & 3.20 & 0.03 \\
\hline Adjusted & $5.60^{\dagger}$ & 3.70 & $2.84^{\dagger}$ & 1.96 & 2.66 & 0.052 \\
\hline
\end{tabular}

Adjusted analyses included age, sex, length of diagnosis, smoking packyears, chronic obstructive pulmonary disease severity (forced expiratory volume in $1 \mathrm{~s}$ ), and time between recruitment and previous exacerbation as covariates. *Significantly different from normal weight; ${ }^{\dagger}$ Trend toward a difference from normal weight

that patients with low BMI (ie, underweight) would be at greater risk for both inpatient- and outpatient-treated exacerbations relative to patients with normal BMIs. Our hypothesis was only partially confirmed: we found that relative to normal weight patients, being underweight conferred a greater risk for inpatient- but not outpatient-treated exacerbations. When examining the annual rates of any exacerbation, the analyses revealed a main effect of BMI, which was driven by an increased rate in underweight patients and a decreased rate in overweight patients, both compared with normal weight patients. In addition, for annual rates of inpatient-treated exacerbations, the results showed a significant reduction in the number of these exacerbations 
TABLE 3

Relative risk (RR) of experiencing a first exacerbation as a function of body mass index group

\begin{tabular}{lcccc}
\hline & \multicolumn{4}{c}{ Body mass index group } \\
\cline { 2 - 5 } & \multicolumn{4}{c}{ Normal } \\
weight \\
Adjusted RR & Underweight & $(n=41$ & Overweight & Obese \\
$(95 \% \mathrm{Cl})$ & $(n=10[9 \%])$ & $[36 \%])$ & $(n=38[33 \%])$ & $(n=26[22 \%])$ \\
\hline
\end{tabular}

Outpatient-treated exacerbations

\begin{tabular}{cccccc} 
Unadjusted & $1.22(0.60-2.46)$ & 1 & $0.90(0.56-1.44)$ & $0.82(0.48-1.39)$ \\
Adjusted & $1.09(0.52-2.29)$ & 1 & $1.11(0.68-1.81)$ & $0.99(0.56-1.75)$ \\
Inhospital-treated exacerbations & & & \\
$\begin{array}{l}\text { Unadjusted } \\
\text { Adjusted }\end{array}$ & $2.56(1.64-7.72)$ & 1 & $0.63(0.35-1.10)$ & $0.96(0.53-1.72)$ \\
$\begin{array}{l}\text { Any exacerbations } \\
\text { Unadjusted }\end{array}$ & $1.09(0.52-2.92)$ & 1 & $1.11(0.68-1.81)$ & $0.99(0.56-1.75)$ \\
Adjusted & $1.21(0.57-2.56)$ & 1 & $0.85(0.52-1.37)$ & $0.96(0.56-1.65)$ \\
\hline
\end{tabular}

Adjusted analyses included age, sex, length of diagnosis, smoking pack-years, chronic obstructive pulmonary disease severity (forced expiratory volume in $1 \mathrm{~s}$ ) and time between recruitment and previous exacerbation as covariates

in overweight patients compared with normal weight patients. Finally, we found no significant impact of BMI on outpatient-treated exacerbations.

Our findings linking underweight to a nearly threefold increased risk for inpatient-treated exacerbations are consistent with those reported by Oostenbrink and Rutten-van Mölken (7), who found that the risk of COPD hospitalization was 3.6 times higher for COPD patients with a low BMI $\left(<18.5 \mathrm{~kg} / \mathrm{m}^{2}\right)$ compared with all other BMI categories (RR 3.62 [95\% CI 1.50 to 8.71]). In addition, Schembri et al (9) found that being underweight tended to be associated with a higher risk of COPD-related hospitalization and all-cause mortality (HR 1.23 [95\% CI 0.94 to 1.81]) in 3343 COPD patients followed over a five-year period. However, the findings of Schembri et al are difficult to directly compare with ours because the authors did not report the specific impact of BMI on COPD hospitalizations versus COPD-related mortality separately. Also of note, only $33 \%$ of the 550 recorded deaths were reported to have been attributable to respiratory causes, which further complicates the interpretation of the results.

Of note, we also found that overweight patients had a significantly reduced annual rate of inpatient-treated exacerbations compared with the normal weight group, suggesting that being over (rather than normal) weight may be a protective factor for inpatient-treated exacerbations in this population. These findings are consistent with at least two previous studies that found a linear relationship between higher BMI and a decreased risk of hospitalization and mortality among overweight COPD patients $(9,20)$. Although this may appear to provide further support to the extant literature on the possible protective effects of increased weight in COPD patients relative to patients with other chronic conditions (eg, cardiovascular disease, diabetes) (17), the fact we did not find any protective effect of obesity suggests that extreme overweight may not confer any benefits for COPD patients and contradicts the linear association found in the aforementioned studies $(9,20)$.

Potential mechanisms relating body weight to COPD exacerbations

Body composition: Although our study was not designed to assess the mechanisms linking BMI to the risk for COPD exacerbations, we can speculate on some of the potential pathways. First, body composition and the relative amounts of fat and muscle mass depletion that may characterize our underweight patients may be driving our findings, because the loss of fat-free mass has been shown to impair respiratory muscle function and respiratory muscle strength (21). It has also been suggested that fat mass plays an important role in energy homeostasis and physiological regulation by producing leptin (22). For example, leptin has been implicated in feedback mechanisms regulating feeding behaviour, energy balance and lipid metabolism $(23,24)$. Increased leptin levels have also been associated with reduced systemic inflammation (24), although this may be via an individual nutritional status (which is usually better in patients with higher BMI than in patients with lower BMI [23]), rather than a direct effect. Due to the links among leptin, BMI and systemic inflammation, it is possible that COPD patients with lower BMIs may have lower levels of leptin, which then translates to increased inflammation and a greater chance of experiencing an exacerbation. With regard to our findings linking overweight to reduced exacerbation risk, it has been suggested that overweight COPD patients are better protected from a decrease in body cell mass during periods of exacerbations because of higher energy reserves (25). However, it remains uncertain whether the changed rates of exacerbation is attributable to a protective effect of a higher body fat mass, higher fat free mass or a combination of the two.

COPD phenotype: Another possible explanation linking low BMI to an increased risk for COPD exacerbations is via the different phenotypes of COPD. Two phenotypes of COPD have been traditionally distinguished: emphysema (the 'pink puffers') and chronic bronchitis (the 'blue bloaters') (26). Emphysematous patients may be more likely to be underweight (27) because of the increased amount of effort required to breath, which may result in greater overall sustained energy expenditure and lower weight (28). It has been suggested that emphysematous patients (who are typically known to suffer from breathlessness [26], reduced carbon monoxide diffusion capacity [29] and malnutrition [30]) experience different clinical manifestations of exacerbations characterized by more 'silent' symptoms (ie, less cough and expectorations than typically seen in patients with chronic bronchitis) (26). As such, these patients may be less likely to perceive their symptom deterioration and delay the initiation of their self-management action plan at the onset of symptoms. As a result, they may only perceive symptoms once they reach an advanced state, increasing the risk of a hospital event. The fact that we did not observe any statistically significant associations between being underweight and outpatienttreated exacerbations, which rely on patient detection and early intervention on symptoms, provides some support for this hypothesis. Behavioural factors: A potentially important behaviour of note is smoking. An examination of the data revealed that a significantly larger proportion $(60 \%)$ of underweight patients were current smokers at baseline relative to all other BMI groups (10\% to $46 \%$ ). Given the importance of smoking in the etiology of COPD, we had included pack-years (a more accurate representation of cumulative smoking over time) rather than smoking status as a covariate in the analyses. The increased smoking prevalence in the underweight group was unexpected. As such, this increased rate of smoking may have resulted in a more rapid deterioration in COPD symptoms and could partially explain the higher risk for inpatient-treated exacerbations in this group. We performed a sensitivity analysis including current smoking as the covariate rather than pack-years, and the results remained the same (RR 2.93 [95\% CI 1.25 to 6.85]). Therefore, current smoking is unlikely to account for this relationship.

\section{Study limitations and strengths}

The present study has some limitations that should be considered when interpreting the results. First, our sample was a modest convenience sample drawn from outpatient clinics and not from a general COPD population, which may limit the generalizability of our findings. However, we included a representative sample of moderate to severe COPD patients that were recruited from both an urban and a suburban hospital, with equal proportions of men and women.

Second, the negative finding concerning BMI and outpatienttreated exacerbation risk in the underweight group could be due to the small sample size and the lack of power in this subgroup. Therefore, we cannot definitively conclude that BMI has no impact on outpatienttreated exacerbation risk in underweight patients. However, the 
relatively small effect size apparent in these analyses suggests that if there is an effect, it is not large. Third, most of the patients in the present study had participated in a self-management program that may have limited our ability to generalize findings to COPD patients who do not benefit from access to such programs. However, these selfmanagement programs are common in North America and in Europe $(31,32)$. In addition, we used a clinical event-based definition of exacerbations; therefore, we did not measure physiological markers of an exacerbation (eg, inflammatory responses) (14). Consequently, it is exceedingly difficult to quantify the precise onset, severity and recovery time of each exacerbation. However, all exacerbations were verified by a systematic chart review, and the definition used was consistently applied and corresponded to standard definitions found in the literature (3). Finally, we did not have a measure of body composition or regional fat distribution; as such, we were not able to disentangle the impact of fat versus muscle mass on exacerbations. Unfortunately, we also did not have measures of BMI or body composition at the follow-up; therefore, we could not assess the potential impact of change in BMI on exacerbations. However, these provide the basis for future studies.

Despite some limitations, the present study also has a number of strengths. First, to our knowledge, the present prospective study was the first to use measured height and weight to assess the link between BMI and risk for both in- and outpatient-treated exacerbations, the latter of which rarely, if ever, have been assessed in relation to BMI. Second, the present study included objective measures of pulmonary function (ie, $\mathrm{FEV}_{1}$ ) and BMI. Third, all analyses were adjusted for several important covariates. Fourth, monthly telephone interviews were conducted to assess exacerbation events and all treatments received (which were then verified by chart review), which increases the reliability and validity of the outcome data obtained. Finally, the present study included a long-term (ie, nearly two years) follow-up period, which may increase the chances of observing BMI impact on the occurrence of new exacerbations.

\section{CONCLUSIONS}

The present study was the first to assess the impact of BMI on both in- and outpatient-treated exacerbations and showed that only underweight COPD patients were at greater risk of future inpatient-treated exacerbations. The current study found that patients who were overweight - but not obese - experienced a lower rate of inpatient-treated exacerbations. Finally, we found no impact of BMI on outpatienttreated exacerbations, although this negative finding is potentially inconclusive. These results show that there is an important distinction to make between inpatient-versus outpatient-treated exacerbations to improve our understanding of the relationship between BMI and exacerbations. Finally, future research should investigate the mechanisms underlying the association between low body weight and inpatient-treated exacerbations, and the efficacy of programs designed to improve weight management on future exacerbation risk and quality of life.

ACKNOWLEDGEMENTS: The authors are grateful to Mr Guillaume Lacoste BA and Mr Philippe Stébenne PhD(c) from Hôpital du Sacré-Coeur de Montréal, and the nurses and inhalotherapist from Hôpital du SacréCoeur de Montréal and Hôpital St-Eustache for their invaluable assistance with data collection. The authors also thank Manon Labrecque MD and Andre Cartier MD for their input into the original study.

AUTHORS' CONTRIBUTIONS: AJ contributed to the conception and design of the analyses and the interpretation of the data. She was fully involved in the drafting and revision of this manuscript, and provided final approval of its content ahead of submission. CLA contributed to the conception and design of this study, was fully involved in the acquisition of study data, interpretation of these data and revision of the entire manuscript. KLL contributed to the conception and design of this study, obtained funding for the study, was fully involved in the interpretation of these data and revision of the entire manuscript. She also provided final approval of its content ahead of submission. GM participated in the interpretation of the data and provided corrections to the manuscript. MB provided corrections to the manuscript. CLE provided corrections to the manuscript. SLB contributed to the conception and design of this study. He performed the statistical analysis, was involved in the interpretation of these data and revision of the entire manuscript. He had full access to all of the data in the study and takes full responsibility for the integrity of all of the data. He also provided final approval of its content ahead of submission. All authors read and approved the final manuscript.

DISCLOSURES: All authors do not have financial, consulting or personal relationships with other people or organizations that could influence this work. The authors did not use scientific writing assistance for this study. This study was supported by La Fondation de l'Hôpital du Sacré-Coeur de Montréal, fonds de la succession Gemma Moisan (KLL), as well as by salary awards from the Fonds de la recherche $d u$ Quebec - Santé (FRQS) (KLL and SLB) and the Canadian Institutes of Health Research (CIHR) (SLB and KLL). Scholarship support was provided by the FRQS (CLA, GM), CIHR (GM) and the Fond Québécois de la Recherche sur la Société et la Culture (FQRSC) (AJ).

\section{REFERENCES}

1. Kochanek KD, Xu J, Murphy SL, Miniño AM, Kung HC. Deaths: Preliminary Data for 2009. National Vital Statistics Reports 2011;59:1-57.

2. World Health Organization. Chronic obstructive pulmonary disease (COPD). 2009: Fact sheet N³15 DOI: <www.who.int/mediacentre/ factsheets/fs315/en/index.html> (Accessed November 3, 2010).

3. Burge S, Wedzicha JA. COPD exacerbations: Definitions and classifications. Eur Respir J 2003;21:46S-53.

4. Niewoehner DE. The impact of severe exacerbations on quality of life and the clinical course of chronic obstructive pulmonary disease. Am J Med 2006;119:38-45.

5. Ramsey SD, Hobbs FDR. Chronic obstructive pulmonary disease, risk factors, and outcome trials: Comparisons with cardiovascular disease. Proc Am Thorac Soc 2006;3:635-40.

6. Xu W, Collet JP, Shapiro S, et al. Negative impacts of unreported COPD exacerbations on health-related quality of life at 1 year. Eur Respir J 2010;35:1022-30.

7. Oostenbrink JB, Rutten-van Mölken MP. Resource use and risk factors in high-cost exacerbations of COPD. Respir Med 2004;98:883-91.

8. Hurst JR, Vestbo J, Anzueto A, et al. Susceptibility to exacerbation in chronic obstructive pulmonary disease. N Engl J Med 2010;363:1128-38.

9. Schembri S, Anderson W, Morant S, et al. A predictive model of hospitalisation and death from chronic obstructive pulmonary disease. Respir Med 2009;103:1461-7.

10. Bourbeau J, Julien M, Maltais F, et al. Reduction of hospital utilization in patients with chronic obstructive pulmonary disease: A disease-specific self-management intervention. Arch Intern Med 2003;163:585-91.

11. Worth H. Self management in COPD: One step beyond? Patient Educ Couns 1997;32:S105-9.

12. Calverley PM. COPD: Early detection and intervention. Chest 2000;117:365S-71S.

13. Laurin C, Labrecque M, Dupuis G, Bacon SL, Cartier A, Lavoie KL. Chronic obstructive pulmonary disease patients with psychiatric disorders are at greater risk of exacerbations. Psychosom Med 2009;71:667-74.

14. Seemungal TR, Donaldson GC, Paul EA, Bestall JC, Jeffries DJ, Wedzicha JA. Effect of exacerbation on quality of life in patients with chronic obstructive pulmonary disease. Am J Respir Crit Care Med 1998;157:1418-22.

15. Andersson F, Borg S, Jansson SA, et al. The costs of exacerbations in chronic obstructive pulmonary disease (COPD). Respir Med 2002;96:700-8.

16. Bestall JC, Paul EA, Garrod R, Garnham R, Jones PW, Wedzicha JA. Usefulness of the Medical Research Council (MRC) dyspnoea scale as a measure of disability in patients with chronic obstructive pulmonary disease. Thorax 1999;54:581-6. 
17. Tjepkema M. Adult obesity. Health Rep 2006;17:9-25.

18. Suissa S. Statistical treatment of exacerbations in therapeutic trials of chronic obstructive pulmonary disease. Am J Respir Crit Care Med 2006;173:842-6.

19. Gold PM. The 2007 GOLD guidelines: A comprehensive care framework. Respir Care 2009;54:1040-9.

20. Chailleux E, Laaban JP, Veale D. Prognostic value of nutritional depletion in patients with COPD treated by long-term oxygen therapy: Data from the ANTADIR observatory. Chest 2003;123:1460-6.

21. Engelen MP, Schols AM, Baken WC, Wesseling GJ, Wouters EF. Nutritional depletion in relation to respiratory and peripheral skeletal muscle function in out-patients with COPD. Eur Respir J 1994;7:1793-7.

22. Wouters EFM. Nutrition and metabolism in COPD. Chest 2000;117:274S-280S.

23. Schols AM, Creutzberg EC, Buurman WA, Campfield LA, Saris WH, Wouters EF. Plasma leptin is related to proinflammatory status and dietary intake in patients with chronic obstructive pulmonary disease. Am J Respir Crit Care Med 1999;160:1220-6.

24. Takabatake N, Nakamura H, Abe S, et al. Circulating leptin in patients with chronic obstructive pulmonary disease. Am J Respir Crit Care Med 1999;159:1215-9.

25. Gray-Donald K, Gibbons L, Shapiro SH, Macklem PT, Martin JG. Nutritional status and mortality in chronic obstructive pulmonary disease. Am J Respir Crit Care Med 1996;153:961-6.
26. Filley GF, Dart GA, Mitchell RS. Emphysema and chronic bronchitis: Clinical manifestations and their physiological significance. Aspen Emphysema Conf 1968;9:339-49.

27. Guerra S, Sherrill DL, Bobadilla A, Martinez FD, Barbee RA. The relation of body mass index to asthma, chronic bronchitis, and emphysema. Chest 2002;122:1256-63.

28. Donahoe M, Rogers RM, Wilson DO, Pennock BE. Oxygen consumption of the respiratory muscles in normal and in malnourished patients with chronic obstructive pulmonary disease. Am Rev Respir Dis 1989;140:385-91.

29. Sahebjami H, Sathianpitayakul E. Influence of body weight on the severity of dyspnea in chronic obstructive pulmonary disease. Am J Respir Crit Care Med 2000;161:886-90.

30. Jounieaux V, Mayeux I. Oxygen cost of breathing in patients with emphysema or chronic bronchitis in acute respiratory failure. Am J Respir Crit Care Med 1995;152:2181-4.

31. Chen Y-J, Narsavage GL. Factors related to chronic obstructive pulmonary disease readmission in Taiwan. West J Nurs Res 2006;28:105-24

32. Stehr DE, Klein BJ, Murata GH. Emergency department return visits in chronic obstructive pulmonary disease: The importance of psychosocial factors. Ann Emerg Med 1991;20:1113-6. 


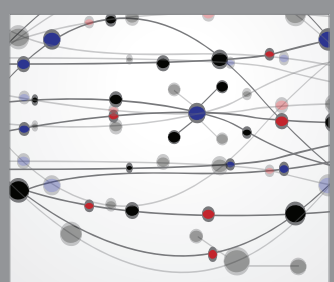

The Scientific World Journal
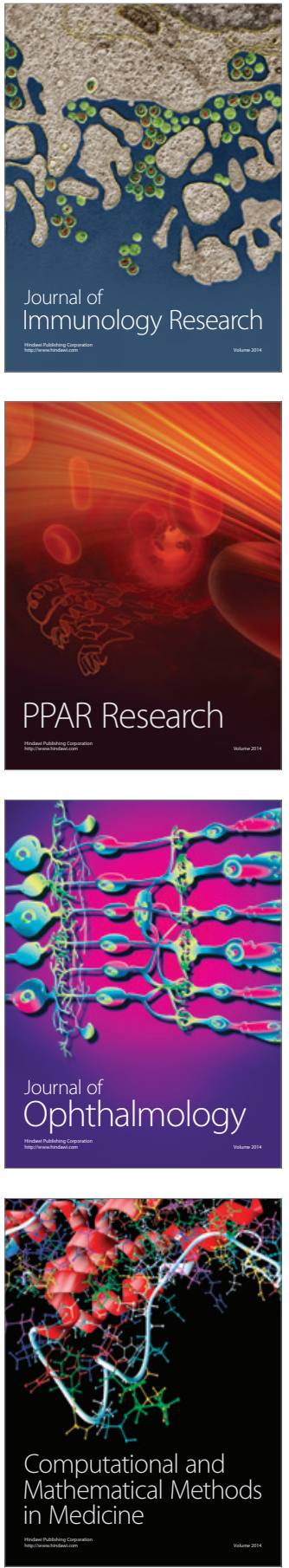

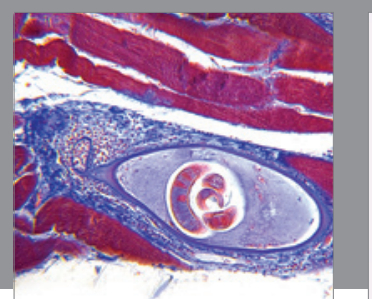

Gastroenterology Research and Practice

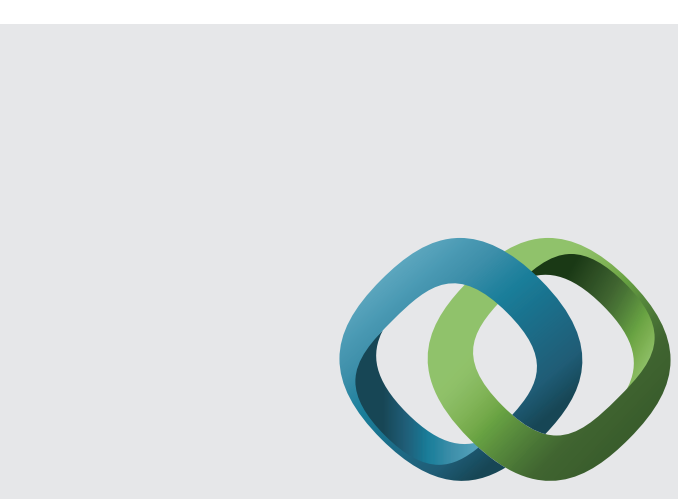

\section{Hindawi}

Submit your manuscripts at

http://www.hindawi.com
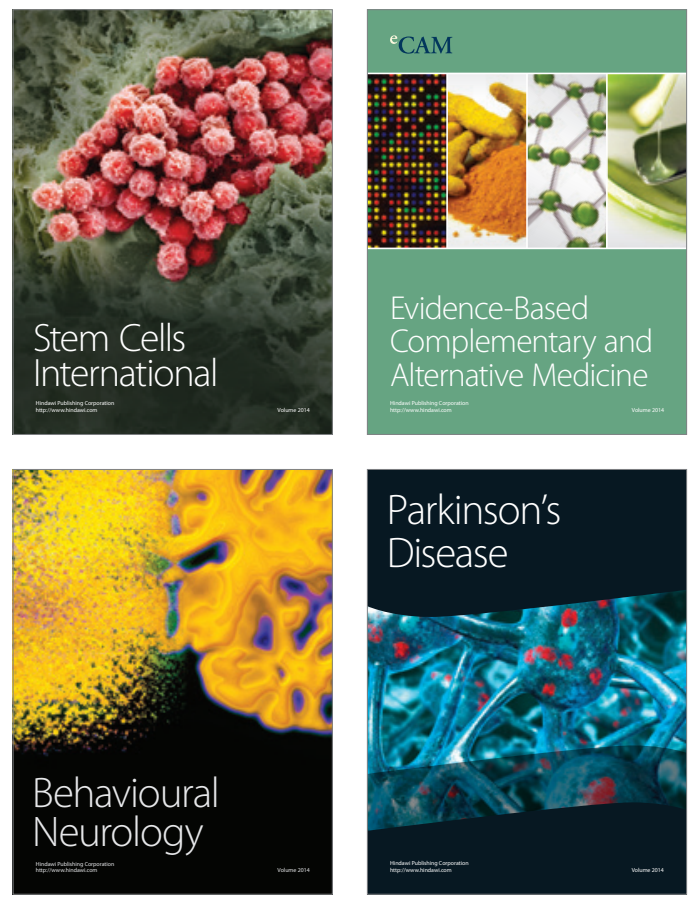
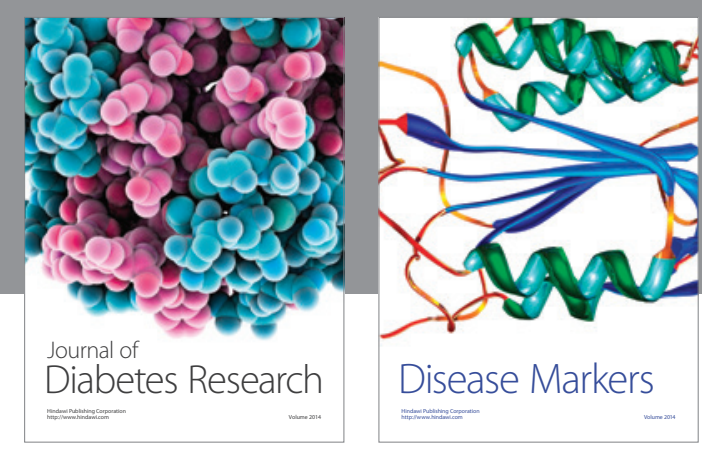

Disease Markers
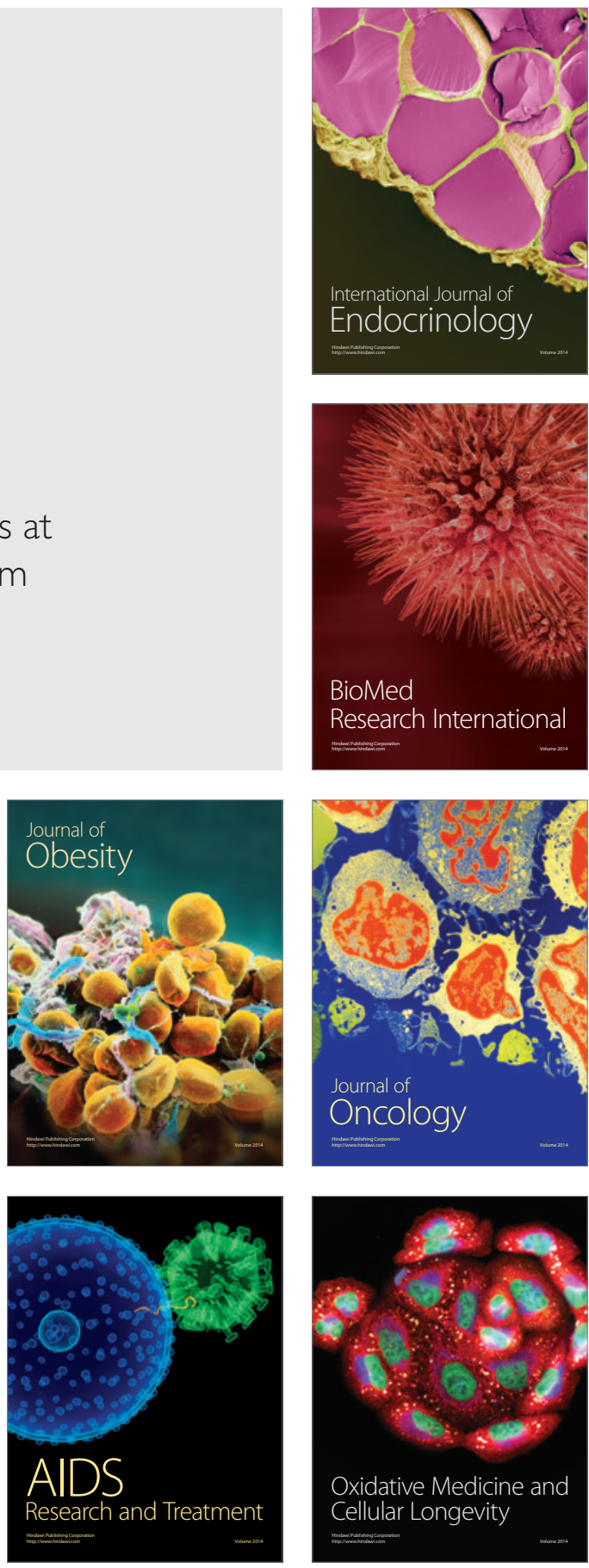